\title{
Large giant cell tumor of the posterior iliac bone - an atypical location. A case report and literature review
}

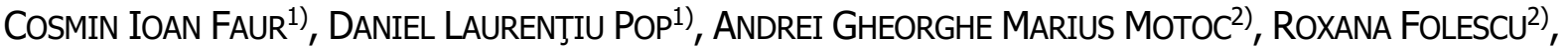

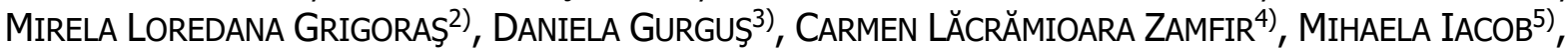

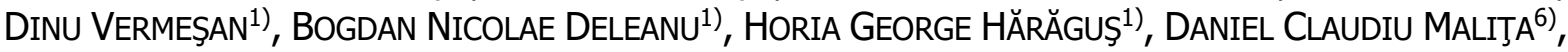 \\ AHMED ABU-AWWAD ${ }^{1)}$, ION LUCIAN GHIGA ${ }^{1)}$, MARIANA TUDORAN ${ }^{7}$ )
}

\author{
1) Department of Orthopedics and Traumatology, Victor Babeş University of Medicine and Pharmacy, Timişoara, Romania \\ 2) Department of Anatomy and Embryology, Victor Babeş University of Medicine and Pharmacy, Timişoara, Romania \\ 3) Department of Balneology, Medical Recovery and Rheumatology, Victor Babeş University of Medicine and Pharmacy, \\ Timişoara, Romania \\ 4) Department of Morpho-Functional Sciences, Grigore T. Popa University of Medicine and Pharmacy, Iaşi, Romania \\ 5) Department of Pathology, Pius Brinzeu Emergency County Hospital, Timişoara, Romania \\ 6) Department of Medical Radiology and Imagistics, Victor Babeş University of Medicine and Pharmacy, Timişoara, Romania \\ 7)Department of Cardiology, Pius Brînzeu Emergency County Hospital, Timişoara, Romania
}

\begin{abstract}
Giant cell tumor (GCT) is a locally aggressive tumor but with benignity features, representing approximately $18 \%$ of non-malignant bone tumors in European countries, with slight female predominance. Malignancy in GCT is rare, about $<2 \%$ of cases and is more common at older ages. Is known that usually occurs at the epiphyses of long bones, but extremely rare may have another location, such as the pelvic bone. An atypical location - the posterior iliac bone, found at a 34-year-old male -, is the case report we studied and described. Starting from the patient's complains, like a mass in the left buttock region described as "recently appeared", firm, not-mobile, with no distinctive borders and no tenderness at palpation, and a recent history trauma, multiple investigations have been performed, which have highlighted an osteolytic lesion, close to the sacroiliac joint, only with infiltration of the gluteal, iliac and paravertebral muscles. The treatment of choice was hemipelvectomy, with wide tumoral resection, and selective embolization of the nutrient vessels 24 hours prior to the surgical procedure. At two years postoperative, we found a good functional result and the computed tomography (CT) scan revealed no signs of recurrence.
\end{abstract}

Keywords: giant cell tumor, iliac bone, uncommon localization, benign tumor.

\section{口 Introduction}

Giant cell tumor (GCT) of the bone is classified as a primary benign tumor. Despite its benign definition, it is known as being very aggressive locally. Demographical data indicate an incidence of $4-5 \%$ of all primary bone tumors in all ethnical groups, representing approximately $18 \%$ of non-malignant bone tumors in European countries [1]. It is more common in China and India, being responsible for approximately $20 \%$ of primary bone tumors [2]. Regarding gender distribution, GCTs are slightly more common in females. In $<2 \%$ of all cases, the GCT can undergo malignant transformation, and is more common at older ages (30-50 years). Clinical symptoms are nonspecific and may include local pain, deformation and limited movements of the adjacent joint. There is no broad consensus on the choice of the ideal treatment method. There are several accepted surgical techniques, from intra-lesion curettage to wide tumor resection [3].

Localization of this type of bone tumors in flat bones and especially in pelvic bone is extremely rare, GCT typically affecting the ends of long bones such as distal femur, proximal tibia, distal radius, and proximal humerus in the order of frequency [4].

\section{Aim}

This report describes the case of a 34-year-old patient presenting a GCT of the posterior part of the iliac bone with unique features regarding its dimensions, localization, and imaging.

\section{ㅁ Case presentation}

A 34-year-old male was referred to Department of Orthopedics and Traumatology, Pius Brînzeu Emergency County Hospital, Timişoara, Romania, by its general practitioner. The main complaint was a mass in the left buttock region described by the patient as "recently appeared". Other secondary complaints as small intensity dull pain with no irradiation and difficulties at sitting were also mentioned by the subject. From the history data, we noted a pelvic trauma, six months prior to the first medical examination in our Department.

Local clinical examination revealed a firm mass located in the left gluteal region, with no tenderness at palpation, palpable lymph nodes but not significantly enlarged. The tumor was firm, not mobile with no distinctive borders. We found no pallor, clubbing, cyanosis, icterus, or edema.

This is an open-access article distributed under the terms of a Creative Commons Attribution-NonCommercial-ShareAlike 4.0 International Public License, which permits unrestricted use, adaptation, distribution and reproduction in any medium, non-commercially, provided the new creations are licensed under identical terms as the original work and the original work is properly cited. 
Blood pressure, peripheral pulse was normal. Abdominal and urological exams revealed no significant problems.

The preoperative biological parameters were normal including hemoglobin, leukocytes, inflammatory markers: erythrocyte sedimentation rate (ESR), C-reactive protein (CRP), alkaline phosphatase and acid phosphatase.

The patients presented no temperature rise, redness or engorged vessels.

Regular X-ray series were performed (anteroposterior - AP, lateral, obturator views) indicating an osteolytic lesion located in the posterior left iliac wing close to the sacroiliac joint. The tumoral mass had large dimensions, approximately $8 \mathrm{~cm}$ on AP view, was extending in the soft tissues, leaving a small bony-shell at that level - the so-called "ballooning sign" or "soap bubble".

After analyzing the clinical and history data and also the paraclinical investigations at that point, the surgical team reached conclusion such as the "ballooning sign" is indicating an aggressive tumor but might also be a benignity sign.

When considering all the data: age, previous trauma and X-rays the most possible diagnosis might be an aneurysmatic bone cyst.

Other differential diagnosis that have to be kept in our attention were: unique bone metastasis (most frequent renal), malignant histiocytoma, GCT or teleangientatic osteosarcoma; last two less probable.

The following imaging exams were required as further steps: a computed tomography (CT) scan with terminal aorta and left iliac trunk angiography. The reason for this exam was to assess the vascularization of the tumor and also to check the presence and extent of intralesional fluid levels (a common finding in aneurysmal cyst and teleangientatic osteosarcoma) and intralesional necrosis (renal bone metastasis and malignant histiocytoma usually are accompanied by different degrees of necrotic tissue). A special requirement for the Department of Radiology was that the patient has to be kept 15-20 minutes in a supine position prior to the exam for a better assessment of the fluid levels.

Pulmonary and abdominal CT scan in order to exclude the presence of extraskeletal primary or secondary tumors.

A pelvic magnetic resonance imaging (MRI) for in

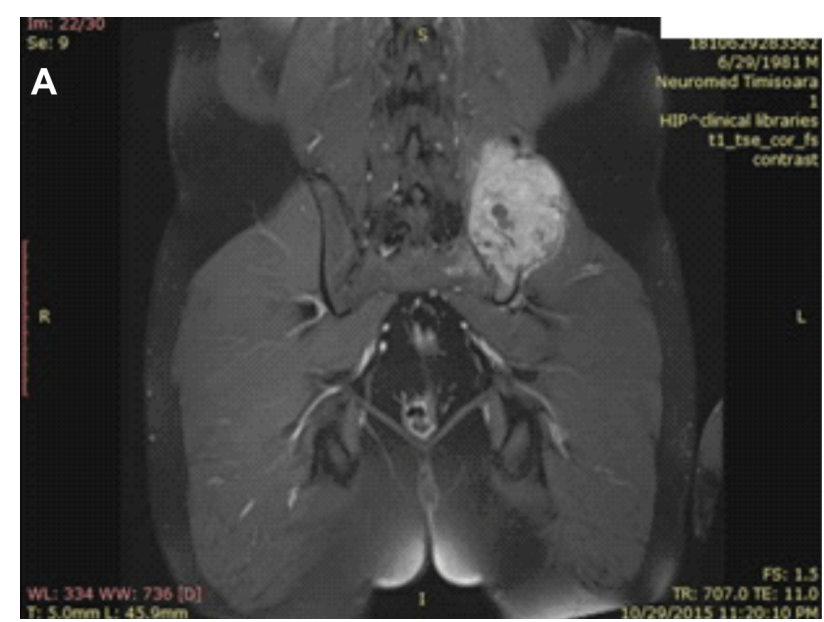

order to assess the extent of the tumor in the soft tissues and for preoperative planning (Figure 1, A and B).

MRI examination showed: large lytic iliac bone tumor $8.14 / 7 / 10.8 \mathrm{~cm}$, close to the sacroiliac joint, with a small cystic central component, infiltration of the gluteal, iliac and paravertebral muscles. No inguinal or pelvic adenopathy, urinary bladder and prostate were found to the normal.

Pulmonary and abdominal CT: normal findings.

Pelvic angio-CT: 7/6.91/9.35 cm tumoral mass with no fluid levels in the close vicinity of the sacroiliac joint with extent in the gluteal and paravertebral muscles at the level of L4-S1. The major arterial supplies come from superior gluteal artery and also some ilio-lumbar branches (Figure 2, A and B).

Hemipelvectomy (wide tumoral resection) was selected the method of treatment of choice, with one-piece resection of the tumor and selective embolization of the nutrient vessels 24 hours prior to the surgical procedure without preoperative bone-needle biopsy.

Axial CT scan reveals a large osteolytic mass located at the postero-superior area of the bone, close to the sacroiliac joint, destroying the cortical bone and infiltrating muscles of the gluteal region (Figure 3A), while the cortex on the posteroinferior part of the iliac bone at the sacroiliac border has a normal aspect (Figure 3B).

Following hemipelvectomy, the specimen was measuring $12 \times 9.5 \times 8 \mathrm{~cm}$, external surface was dark red colored, friable, with solid, cystic and hemorrhagic areas. Selective embolization was performed 24 hours before the main surgery. This proved to be an effective method for bleeding control throughout the whole procedure.

From the resection piece (Figure 4) sent to the Laboratory of Pathological Anatomy, fixed in $10 \%$ neutral buffered formalin, multiple sections were made from the areas of macroscopic interest (some parts of the piece required decalcification), which after inclusion in the paraffin were cut into the microtome (3-4 $\mu \mathrm{m}$ thick) and stained with the usual Hematoxylin-Eosin (HE). No additional immunohistochemically stainings were required.

Postoperative CT at two years postoperative revealed no signs of recurrence and a good functional result (Figure 5, $\mathrm{A}$ and $\mathrm{B})$.

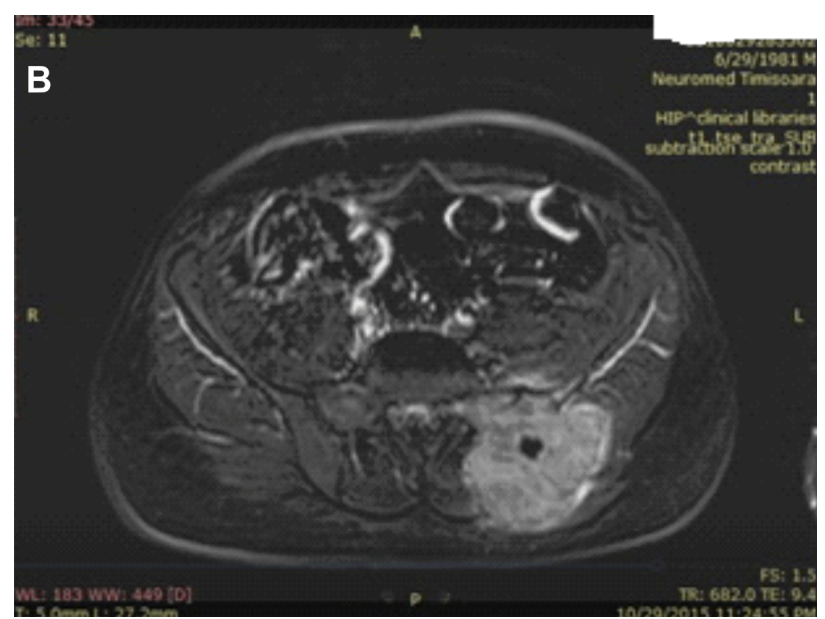

Figure 1 - (A and B) Coronal and axial T1 MRI images showing a posterior left iliac bone tumor. MRI: Magnetic resonance imaging. 

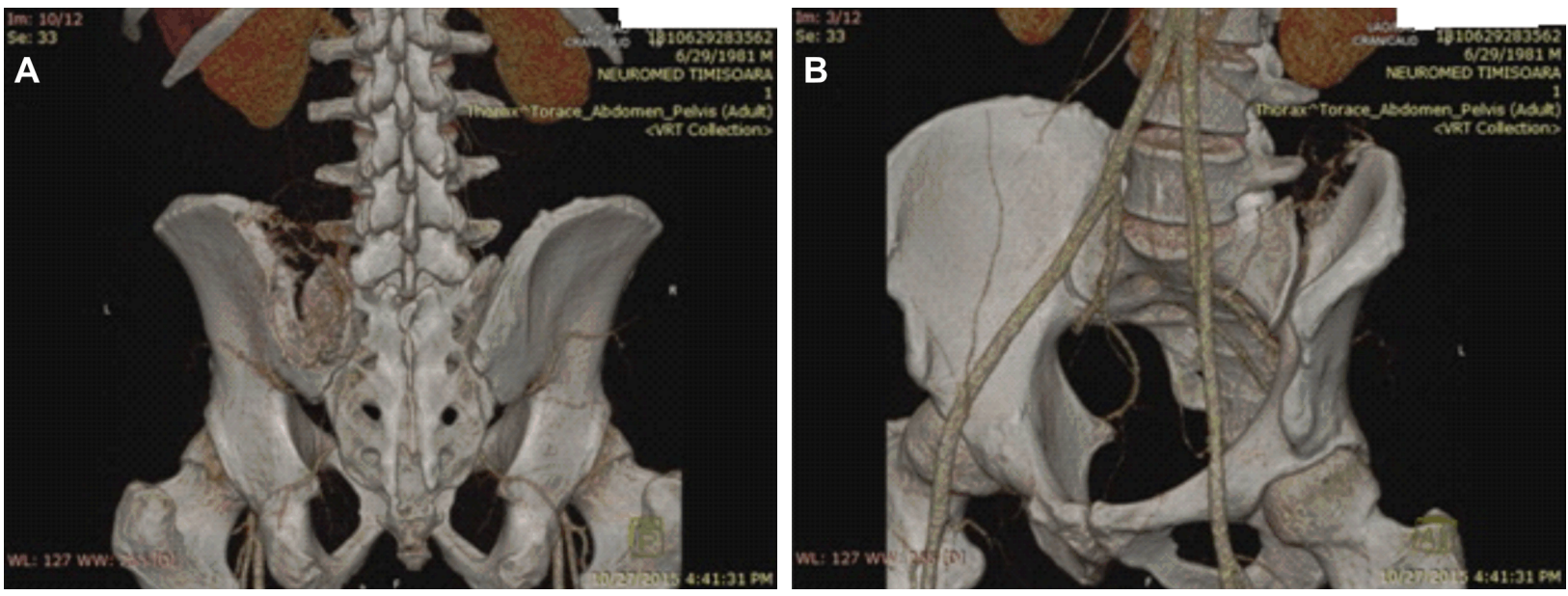

Figure 2 - (A and B) Pelvic angioCT indicating the tumoral vascularization and the nutrient vessels of the lytic lesion. CT: Computed tomography.
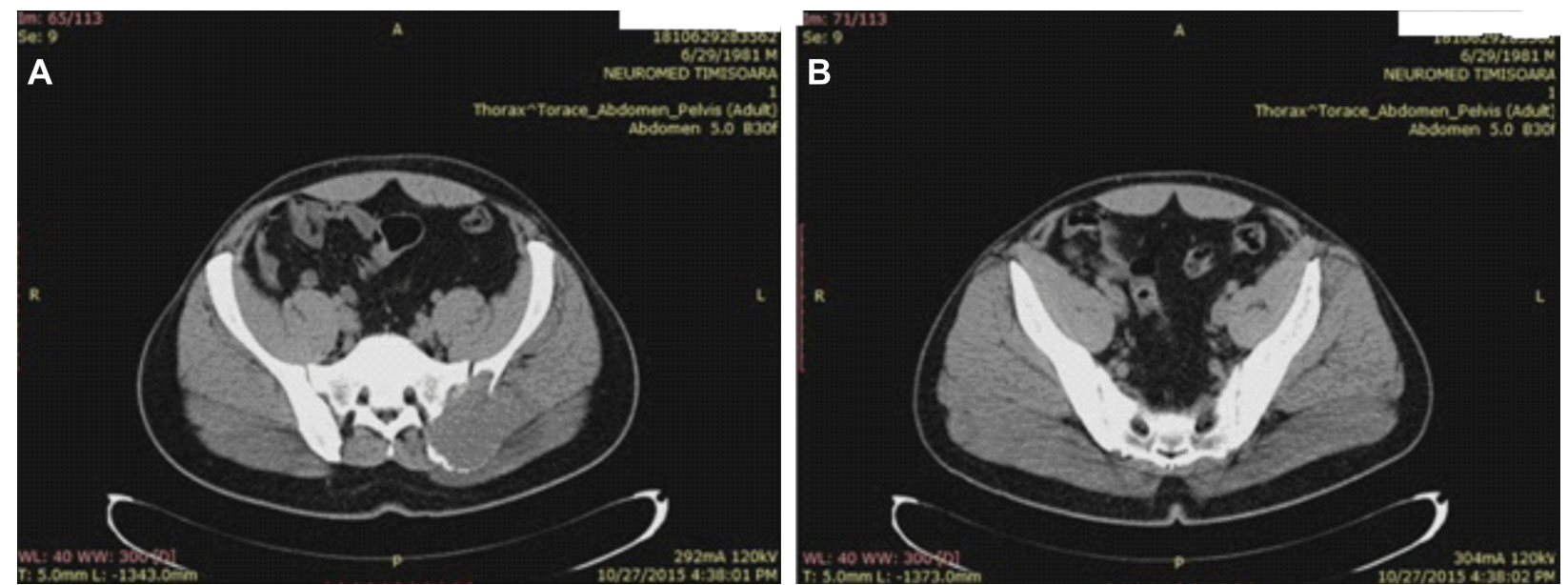

Figure 3 - Axial pelvic CT scan indicating lytic iliac bone tumor: (A) Posterosuperior destruction of the iliac bone; (B) Good posteroinferior bone stock of the iliac bone at the sacroiliac border. CT: Computed tomography.

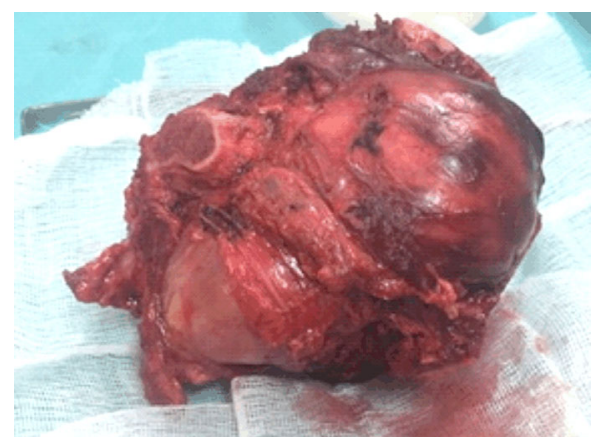

Figure 4 - Post-resection specimen.

Postoperative histopathology established the diagnosis of GCT of the iliac bone, with the morphological picture characteristic of this lesion: tumor proliferation combining two complex cellular contingencies, represented by benign, oval or discreet mononuclear tumor cells and numerous multinuclear giant cells of the large osteoclastic type, evenly distributed among the mononuclear cells and displaying the same nuclear traits with these (Figures 6 and 7). The examination of the multiple processed sections revealed partial destruction or total in other cortical bone areas (Figures 8 and 9), invasion of periosteal soft tissues (periosteum, tenomuscular insertion and layer of muscle tissue) and occasional formation, limited by immature bone, reactive (Figures 10 and 11), to the periphery of the infiltrating tumor. The marked resection limits were not tumor-related.

\section{ㅁ Discussions}

The bone is the complex morphological structure, consisting of several tissues, such as cortical or Haversian bone, spongy bone with the compartment of the hematogenous marrow and the periosteum, which is a connective tissue. Despite its inert appearance, the bone is an extremely dynamic organ, which is continuously resorbed by osteoclasts and unformed by osteoblasts. Under pathological conditions, the bone may be the site of inflammatory or tumor processes [5-8].

From the all tumors of bone, GCT is still one of the most obscure and intensively examined. Its histogenesis is uncertain. According to World Health Organization (WHO), GCT is classified as "an aggressive, potentially malignant lesion", which means an unpredictable evolution based on its histological features. GCTs have a benign course in $80 \%$ of cases and an estimated locally recurrence of $20-50 \%$. The malignant transformation at recurrence is about $10 \%$ of cases and $1 \%$ to $4 \%$ give pulmonary metastases even in cases of benign histology [9]. 

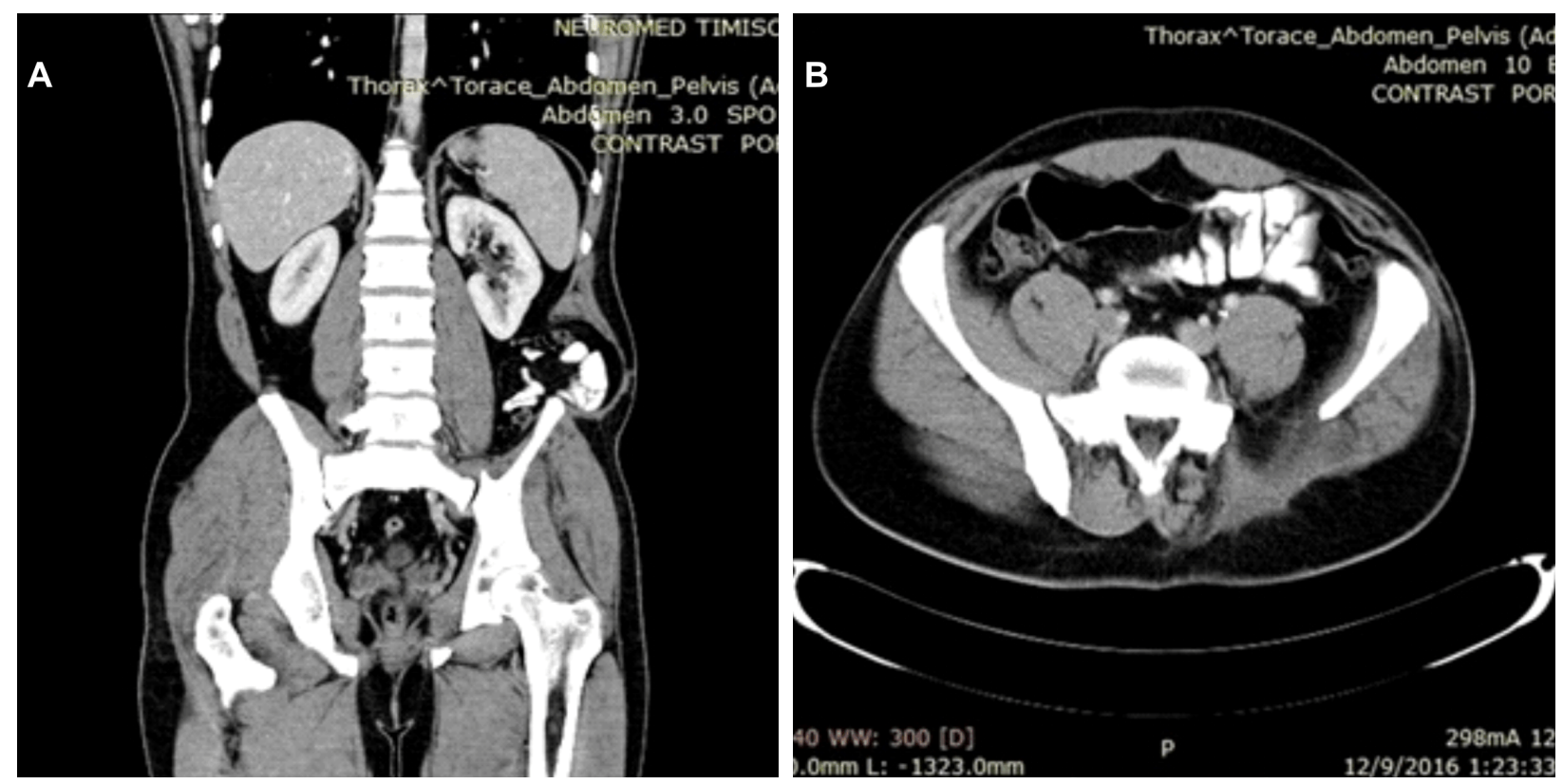

Figure 5 - Coronal and axial pelvic CT scan at two years postoperative showing no signs of local recurrence. CT: Computed tomography.

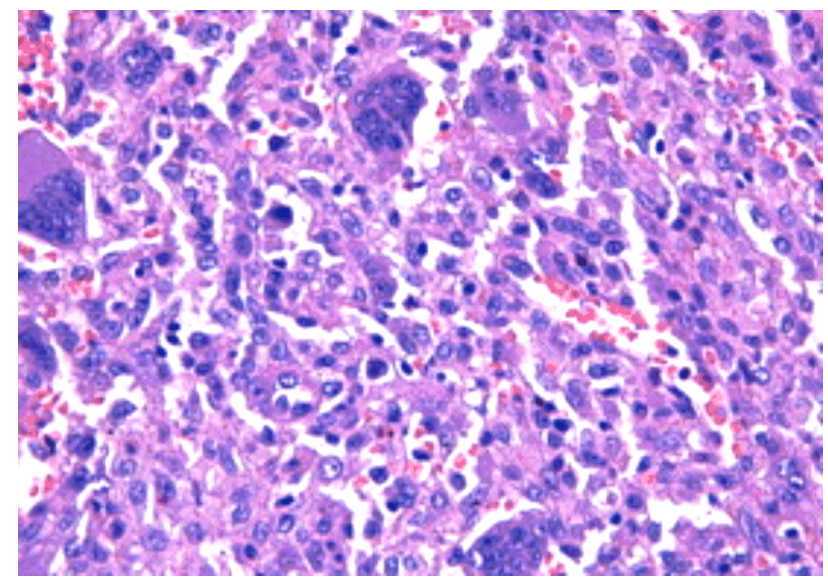

Figure 6 - Giant cell tumor of bone. Detail frame: mononuclear cells intricate multinuclear giant cells with the same nuclear traits in both cellular contingencies (HE staining, $\times 400)$.

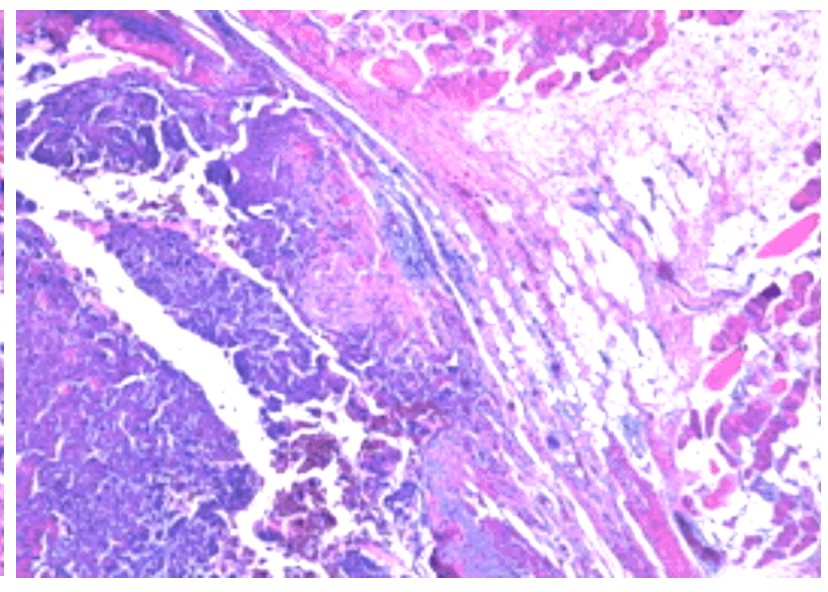

Figure 7 - Giant cell tumor of bone. Discrete fusiform mononuclear cells among multi-nucleated giant cells of uniformly distributed osteoclastic type (HE staining, $\times 40$ ).

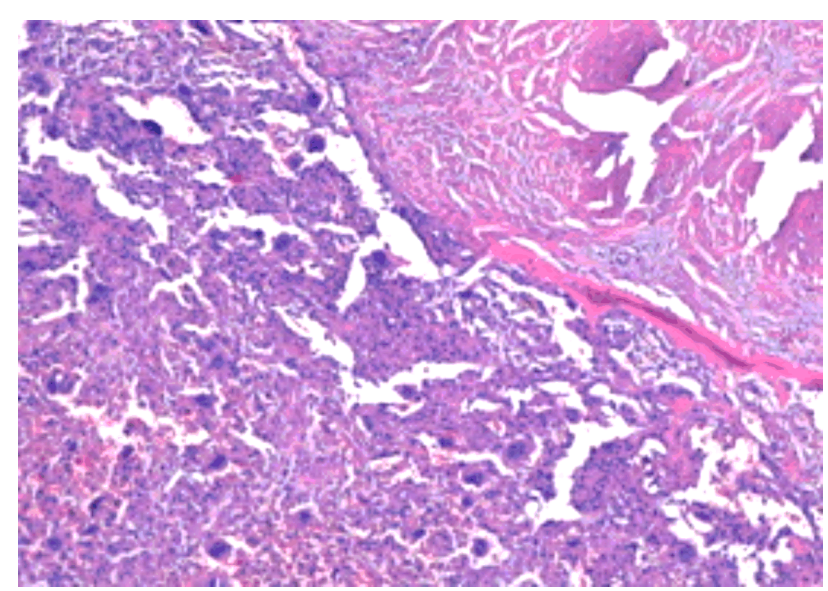

Figure 8 - Area of partial destruction of the cortical bone through the giant cell tumor (HE staining, $\times 40)$.

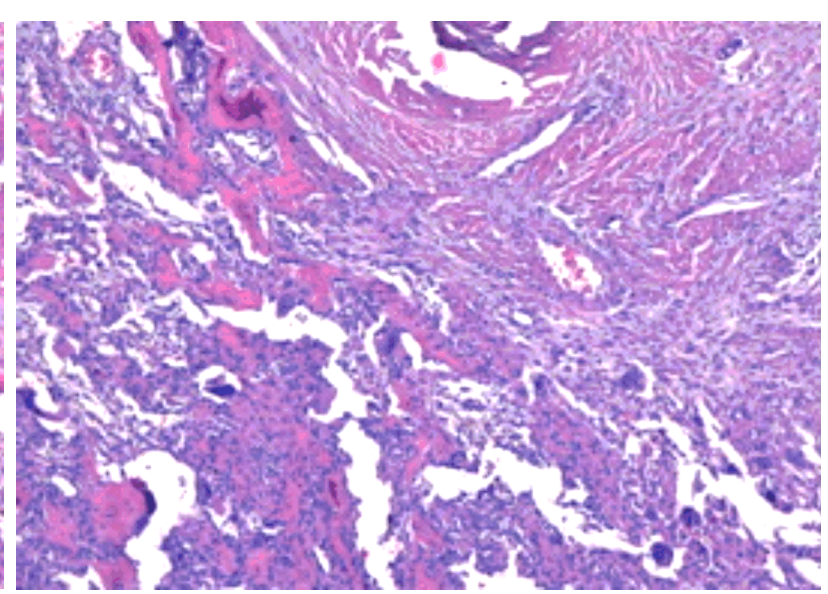

Figure 9 - Cortical bone erosion with the extension of the giant cell tumor in the soft tissues (HE staining, $\times 40)$. 


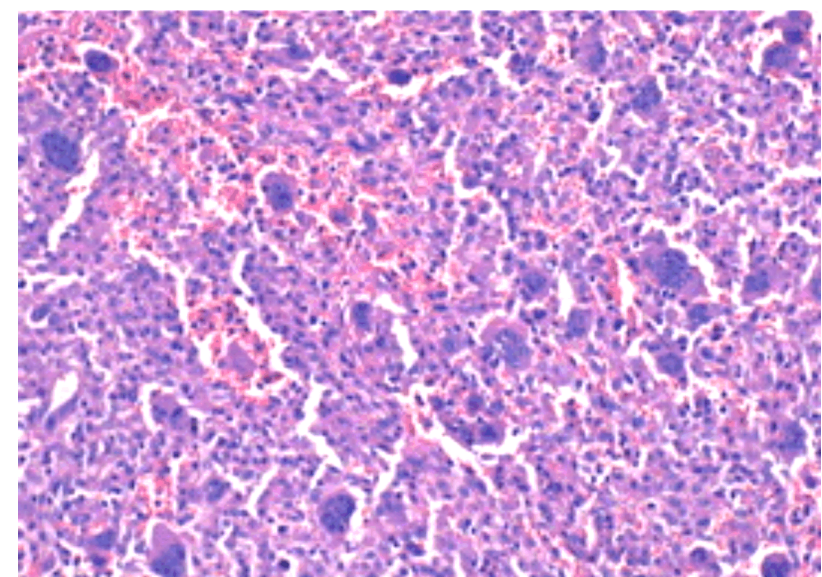

Figure 10 - Giant cell tumor of bone. Peripheral focal immature reactive bone formation (HE staining, $\times 100)$.

If we refer to pelvic GCT, this localization is more uncommon for this type of bone tumor accounting for only 1.5 to $6 \%$ of cases of GCT [10]. It typically presents in adults between ages of 20 to 50 , females being slightly more affected than males [11].

There is no widely held consensus regarding the ideal treatment method selection. When we speak about primary, surgical treatment, there are two major options at that point: intralesional curettage with high recurrence rates and wide resection with improved recurrence rates but sometimes with poor functional outcomes. The goals of treatment are eradication of the tumor with a minimal complication rate and preservation of limb function. The surgical treatment should be associated with adjuvant methods in order to facilitate better local control and prevent recurrences [12].

Zheng et al., in probably the most comprehensive literature review regarding pelvic localization of GCTs, found a total of 165 patients in a retrospective study on a 45 years long period of time. The acetabular area was found to be the most frequent site for pelvic GCT (60 patients), followed be iliac bone (48 patients) and ischiopubic region (31 patients). The complication rate for this type of tumors is quite significant (27 patients). Wide resection being considered a reasonable method of treatment because of the lower recurrence rate especially in extensive and aggressive GCT's [13]. In addition, the posterior localization for the iliac bone was exceptional - only two cases ( $1.2 \%$ of pelvic GCT).

In a series of 19 cases of pelvic GCT by Sanjay et al. [11], iliac localization was found to be the most frequent for this region. Surgical treatment (intra or extralesional resection) was continued with radiotherapy, which proved to be ineffective in lowering the recurrence rate.

Kattapuram et al., in their series of seven cases of GCT of the pelvic bone over a period of 20 years found nine cases involving the ilium [14]. In his 20-patient series of GCT of innominate bones over a period of 20 years, Balke et al. found four cases of posterior iliac localization [15-19].

Several ideas are arising following our case. First of all, the diagnosis of a GCT of the pelvis may be delayed and challenging, and usually the diagnosis of GCT is not the first choice even in the hands of experienced practitioners. In our case, the duration of symptoms

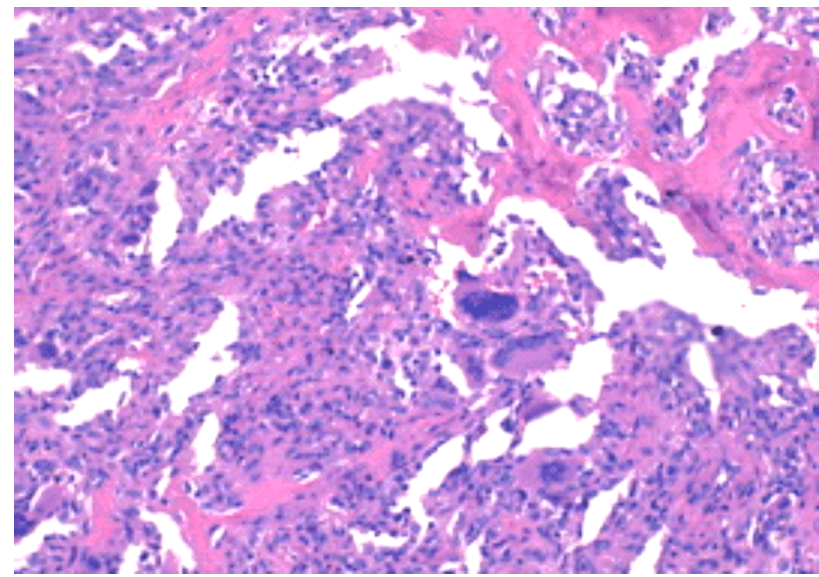

Figure 11 - Bone dispersion of giant cell tumor (HE staining, $\times 100$ ).

since the traumatic episode was six months, which is a quite short period of time for a $10 \mathrm{~cm}$ benign tumor to develop. We appreciate that several factors might be involved in this delayed diagnosis: difficult identification in radiological exams - GCT is a purely lytic destruction of bone which may not be recognized on plain radiographs during the early stage of the disease or lytic areas may be confused with the appearance of gas in the bowel, development of these masses in places where the clinical presentation of these lesions may be confused with other conditions (hip pain, low back pain, or sacroiliac joint pathology). We should always focus on this type of tumor even in an uncommon region like the pelvic girdle, especially in female patients between $30-50$ years old and with potential history of trauma.

The posterior iliac site for GCT requires a thorough preoperative planning. Perhaps the most difficult technical problem of this case was to assess whether the remaining bone stock following wide resection of the posterior iliac bone will be sufficient for a good functional result in a young adult. We found selective embolization of the nutrient tumoral arteries a very helpful tool for intraoperative bleeding control.

Multinuclear GCTs grow not only in the bone but also in other mesenchymal tissues and even in the blood vessels [20].

In this case, based on the benign characteristics of the tumor - well-defined margins, the ballooning sign, our decision was not to perform a preoperative needle biopsy.

\section{a Conclusions}

In the presence of a lytic lesion in the iliac bone with recent history of trauma, in patients between $30-50$ years old, orthopedic practitioners should include GCT through the suspected differential diagnosis. GCT is an aggressive benign bone tumor, localized especially at the end of long bones, most commonly around the knee joint. Iliac localization is a rare finding and the posterior iliac site is extremely rare. Special surgical planning is required with localization of this type of tumor in the neighborhood of the sacroiliac joint. The amount of bone stock left after resection has to be well assessed, and if its required reconstruction options of the pelvic ring have to be considered, in order to achieve normal postoperative 
function and biomechanics of the pelvic girdle. Selective preoperative embolization of the nutrient arteries is an effective tool for intraoperative bleeding control.

\section{Conflict of interests}

Authors declare no conflict of interests.

\section{References}

[1] Campanacci M, Baldini N, Boriani S, Sudanese A. Giant-cell tumor of bone. J Bone Joint Surg Am, 1987, 69(1):106-114. PMID: 3805057

[2] Sung HW, Kuo DP, Shu WP, Chai YB, Liu CC, Li SM. Giantcell tumor of bone: analysis of two hundred and eight cases in Chinese patients. J Bone Joint Surg Am, 1982, 64(5):755761. PMID: 7045129

[3] Reid R, Banerjee SS, Sciot R. Giant cell tumour. In: Fletcher CDM, Unni KK, Mertens F (eds). Pathology and genetics of tumours of soft tissue and bone. World Health Organization (WHO) Classification of Tumors, International Agency for Research on Cancer (IARC) Press, Lyon, France, 2002, 310-312.

[4] Borenstein DG, Wiesel SW, Boden SD. Giant cell tumour. In: Borenstein DG, Wiesel SW, Boden SD. Low back and neck pain: comprehensive diagnosis and management. $3^{\text {rd }}$ edition, Elsevier Health Sciences-Saunders, 2004, 482-488.

[5] Coman M, Hîncu M, Şurlin P, Mateescu G, Nechita A, Banu M. Comparative histomorphometric study of bone tissue synthesized after electric and ultrasound stimulation. Rom J Morphol Embryol, 2011, 52(1 Suppl):455-458. PMID: 21424092

[6] Coman M, Hîncu M. Study of bone cells by confocal microscopy in fractures stimulated by ultrasound. Rom J Morphol Embryol, 2013, 54(2):357-360. PMID: 23771081

[7] Florencio-Silva R, da Silva Sasso GR, Sasso-Cerri E, Simões MJ Cerri PS. Biology of bone tissue: structure, function, and factors that influence bone cells. Biomed Res Int, 2015, 2015:421746. https://doi.org/10.1155/2015/421746 PMID: 26247020 PMCID: PMC4515490

[8] Preda SA, Nechita F, Comanescu MC, Albulescu DM, Tuculina MJ, Docea AD, Burada E, Vasile RC, Mitroi M. Evaluation of bone turnover and DXA markers in premature ovarian failure. Rev Chim (Bucharest), 2019, 70(6):2054-2057. https://doi.org/10.37358/RC.19.6.7274

[9] Schajowicz F. Histological typing of bone tumours. World Health Organization, International Histological Classification of Tumours, Springer Verlag, Berlin-Heidelberg, 1993, 20-22. https://doi.org/10.1007/978-3-642-84902-2

[10] Cheng MT, Chen TH, Chen WM, Huang CK, Chiang CC, Su YP. Periacetabular giant cell tumor treated with intralesional excision and allograft reconstruction. J Chin Med Assoc, 2004, 67(10):537-541. PMID: 15648290

[11] Sanjay BK, Frassica FJ, Frassica DA, Unni KK, McLeod RA, Sim $\mathrm{FH}$. Treatment of giant-cell tumor of the pelvis. J Bone Joint Surg Am, 1993, 75(10):1466-1475. https://doi.org/10. 2106/00004623-199310000-00007 PMID: 8408135

[12] Turcotte RE. Giant cell tumor of bone. Orthop Clin North Am, 2006, 37(1):35-51. https://doi.org/10.1016/j.ocl.2005.08.005 PMID: 16311110

[13] Zheng K, Wang Z, Wu S, Ye Z, Xu S, Xu M, Hu Y, Yu X. Giant cell tumor of the pelvis: a systematic review. Orthop Surg, 2015, 7(2):102-107. https://doi.org/10.1111/os.12174 PMID: 26033989 PMCID: PMC6583480

[14] Kattapuram AS, O'Donnell RJ, Huszar M, Rosenberg AE, Kattapuram SV, Mankin HJ. Surgical management of innominate giant cell tumour. Clin Orthop Relat Res, 1996, (329): 281-287. https://doi.org/10.1097/00003086-199608000-00035 PMID: 8769463

[15] Balke M, Streitbuerger A, Budny T, Henrichs M, Gosheger G, Hardes J. Treatment and outcome of giant cell tumours of the pelvis. Acta Orthop, 2009, 80(5):590-596. https://doi.org/10. 3109/17453670903350123 PMID: 19916695 PMCID: PMC 2823344

[16] Pop DL, Nodiţi G, Abu-Awwad A, Maliţa DC, Zamfir CL, Grigoraş $M L$, Vermeşan $D$, Prejbeanu R, Hărăguş $H G$, Boşcu AL, Ciupe BC, Deleanu BN, Faur Cl, Folescu R. Alveolar rhabdomyosarcoma in an adolescent male patient - case report and current perspectives. Rom J Morphol Embryol, 2018, 59(4):1247-1252. PMID: 30845308

[17] Alexandru L, Haragus H, Deleanu B, Timar B, Poenaru DV, Vlad DC. Haematology panel biomarkers for humeral, femoral, and tibial diaphyseal fractures. Int Orthop, 2019, 43(7):15671572. https://doi.org/10.1007/s00264-019-04305-1 PMID: 30729272

[18] Pop DL, Folescu R, Deleanu BN, lacob M, Vermeşan D, Prejbeanu R, Maliţa DC, Hărăguş HG, Ciupe BC, Zamfir CL, Nodiţi $\mathrm{G}$. The role of immunohistochemistry in the diagnosis and management of synovial sarcoma. Rom J Morphol Embryol, 2018, 59(2):569-572. PMID: 30173264

[19] Caterev S, Nistor DV, Todor A. Anatomic double-bundle anterior cruciate ligament reconstruction with a free quadriceps tendon autograft. Arthrosc Tech, 2016, 5(5):e1063-e1067. https://doi. org/10.1016/j.eats.2016.05.015 PMID: 27909676 PMCID: PMC5124427

[20] Stanca HT, Suvac E, Munteanu M, Jianu DC, Motoc AGM Roşca GC, Boruga O. Giant cell arteritis with arteritic anterior ischemic optic neuropathy. Rom J Morphol Embryol, 2017, 58(1):281-285. PMID: 28523333

\section{Corresponding authors}

Roxana Folescu, Senior Lecturer, MD, PhD, Department of Anatomy and Embryology, Victor Babes University of Medicine and Pharmacy, 2 Eftimie Murgu Square, 300041 Timişoara, Romania; Phone +40729-104 103, e-mail: roxanafolescu08@gmail.com

Daniel Laurenţiu Pop, MD, PhD, Ist Department of Orthopedics and Traumatology, Pius Brînzeu Emergency County Hospital, Victor Babeş University of Medicine and Pharmacy, 2 Eftimie Murgu Square, 300041 Timişoara, Romania; Phone +40745-996 081, e-mail: daniellaurentiupop@yahoo.com 